\title{
Correction to: Eelgrass Genetic Diversity Influences Resilience to Stresses Associated with Eutrophication
}

\author{
Holly K. Plaisted ${ }^{1} \cdot$ Alyssa B. Novak $^{2} \cdot$ Sarah Weigel $^{3} \cdot$ Anita S. Klein $^{4} \cdot$ Frederick T. Short $^{5}$ \\ Published online: 6 February 2020 \\ (C) This is a U.S. government work and its text is not subject to copyright protection in the United States; however, its text may be subject to foreign copyright \\ protection 2020
}

\section{Correction to: Estuaries and Coasts.}

\section{https://doi.org/10.1007/s12237-019-00669-0}

In the original version of the article, there was an error in the column headings on the second page of Table 7. Low $\mathrm{OM} \times$ $100 \%$ light and Low $\mathrm{OM} \times 58 \%$ light should be High $\mathrm{OM} \times$ $100 \%$ light and High $\mathrm{OM} \times 58 \%$, respectively.

The original article has been corrected.

The online version of the original article can be found at https://oi.org/ 10.1007/s12237-019-00669-0

Holly K. Plaisted

holly_plaisted@nps.gov

1 Northeast Coastal and Barrier Network, US National Park Service, University of Rhode Island, 1 Greenhouse Road,

Kingston, RI 02881, USA

2 Department of Earth and Environment, Boston University, 675 Commonwealth Ave, Boston, MA 02215, USA

3 Byfield, USA

4 Department of Biological Sciences, University of New Hampshire, 38 Academic Way, Durham, NH 03824, USA

5 Department of Natural Resources and the Environment, Jackson Estuarine Laboratory, University of New Hampshire, 85 Adams Point Road, Durham, NH 03824, USA 